\title{
Chemical Studies on the Preparation of Magnetic Nanoparticles Coated with Glycine and its Application for Removal of Heavy Metals
}

\author{
JAWAHER ALZAIDI, EMAN ALZAHRANI and N.R.A. EL-MOUHTY \\ Chemistry Department, Faculty of Science, Taif University, 888-Taif, Kingdom of Saudi Arabia. \\ ${ }^{*}$ Corresponding author E-mail: em-s-z@ hotmail.com \\ http://dx.doi.org/10.13005/ojc/320324
}

(Received: May 22, 2016; Accepted: June 30, 2016)

\begin{abstract}
The aim of this study is the preparation of magnetic nanoparticles and coating with glycine to remove heavy metals such as $\mathrm{Cu}^{+2}$. The magnetic nanoparticles were prepared by co-precipitation method using using ferrous sulphate and potassium nitrate in presence of potassium hydroxide. Different instrumental analysis such as XRD, TEM, SEM and EDAX were used to study the magnetic nanoparticles which produced and comparing it after coated with glycine. The optimum conditions which reflect the high efficiency of removal are $\mathrm{pH} 10$, concentration of the heavy metal $200 \mathrm{ppm}$, dosage $0.05 \mathrm{~g}$ and for $24 \mathrm{~h}$ duration time. Therefore we recommend using magnetic nanoparticles coated with glycine for removal of heavy metals.
\end{abstract}

Keyword: Magnetic nanoparticles, glycine, X-ray diffraction, $\mathrm{Fe}_{3} \mathrm{O}_{4}$, co-precipitation, heavy metals.

\section{INTRODUCTION}

With the rapid development of nanotechnology, magnetic nanoparticles are currently studied widely. magnetic nanoparticles have attracted much attention because of their unique magnetic properties, small size, low toxicity, and widespread application, Iron oxide NPs are one of the most common NPs that could find their way into the water system because of their use in water and soil treatment ${ }^{1}$.

Nanoparticles are good building blocks for developing high-capacity sorbents with modification ability to enhance their affinity and selectivity for purification of contaminated waters. Application of nanoparticles (NPs) as novel adsorbents for removal of pollutants is gaining research interest ${ }^{2}$.

Co-precipitation is the most conventional method and is also used by several commercial production plants for the synthesis of magnetic or black iron oxides. there is problem associated with particles in this size range is their intrinsic instability over longer periods of time. Such small particles tend to form agglomerates to reduce the energy associated with the high surface area to volume ratio of the nanosized particles ${ }^{3}$. 
Moreover, naked metallic nanoparticles are chemically highly active, and are easily oxidized in air, resulting generally in loss of magnetism and dispersibility, coating helps not only in protecting the core shell but is also used in addition of functional groups for specific pollutant removal in water treatment ${ }^{4}$.

Generally, magnetic NPs are surface modified with carboxyl, hydroxyl and amino groups for their specific interactions ${ }^{5}$, The synthesis of magnetite nanoparticles has been intensively developed not only for its fundamental scientific interest but also for many technological applications, the use of magnetite nanoparticles as adsorbents in water treatment provides a convenient approach for separating and removing the contaminants by applying external magnetic fields. Bare magnetite nanoparticles are susceptible to air oxidation and are easily aggregated in aqueous systems ${ }^{6}$. Thus, for the application of these nanoparticles in various potential fields the stabilization of the iron oxide particles by surface modification is desirable. The magnetic structure of the surface layer, which is usually greatly different from that in the core of the nanoparticles, can have a notable effect on the magnetic properties of nanoparticles ${ }^{7}$.

\section{EXPERIMENTAL}

\section{Chemicals and materials}

Iron (II) sulphate heptahydrate, ferrous sulphate $\left(\mathrm{FeSO}_{4} .7 \mathrm{H}_{2} \mathrm{O}\right), \mathrm{M} . \mathrm{wt}=278.01 \mathrm{~g} \mathrm{~mol}^{-1}(98 \%)$, potassium nitrate $\left(\mathrm{KNO}_{3}\right) \mathrm{M} . \mathrm{wt}=101.1032 \mathrm{~g} \mathrm{~mol}^{-1}$, potassium hydroxide $(\mathrm{KOH}) \mathrm{M} . \mathrm{wt}=56.11 \mathrm{~g} \mathrm{~mol}^{-1}$, were purchased from Sinopharm Chemical Reagent Co. Ltd. (Shanghai, China), Glycine $\left(\mathrm{NH}_{2} \mathrm{CH}_{2} \mathrm{COOH}\right)$, sodium hydroxide $(\mathrm{NaOH})$, hydrochloric acid $(\mathrm{HCl})$, copper Sulphate $\left(\mathrm{CuSO}_{4}\right)$, were purchased from BDH Chemicals Ltd. (Poole, UK) and used without further purification. Cylindrical rod magnets $(40 \mathrm{~mm}$ diameter x $40 \mathrm{~mm}$ thick) for settlement of magnetic nanoparticles was purchased from Magnet Expert Ltd. (Tuxford, UK). Distilled water was employed for preparing all the solutions and reagents.

\section{Instrumentation}

Magnetic stirrer and heater from Fisher Scintifi Co Ltd (Shanghai, China). Oven from Memmert (Nuremberg, Germany). PH meter from
Hanna Instruments (Cluj, Romania). Balance from Mettler Toledo Model JB1603c/FACT (Greifensee, Switzerland). Sonicator UltraSonic bath from wiseclean Model WUC-D10H (Wonju, Korea). UV-VIS Spectroscopy Thermo Fisher Scientific, GENESYS 10S VIS (Madison, USA). X-ray diffraction patterns (XRD ) were obtained using Bruker diffractometer D8-advance $\mathrm{CuK}_{\text {á }}$-radiation (Coventry, UK). The transmission electron microscopy (TEM) came from JEOL Ltd. (Welwyn Garden City, UK).Scanning Electron Microscope (SEM ) with unit Energy Dispersive $X$ ray (EDAX) analysis, JEOL JSM 6390 LA Analytical(Tokyo, Japan).

\section{Preparation of magnetic nanoparticles MNPs}

Magnetic nanoparticles were prepared as described else where by Abu Bakar et al.[2]. 1.67g of $\mathrm{FeSO}_{4} \cdot 7 \mathrm{H}_{2} \mathrm{O}$, dissolved in $50 \mathrm{~mL}$ of distilled water, $1.01 \mathrm{~g}$ of $\mathrm{KNO}_{3}$ dissolved in $10 \mathrm{~mL}$ of distilled water, and $2.5 \mathrm{M}$ of $\mathrm{KOH}$ were prepared. Potassium nitrate solution was added to $\mathrm{FeSO}_{4} \cdot 7 \mathrm{H}_{2} \mathrm{O}$ solution and stirring was continued for $30 \mathrm{~min}$. Then, $10 \mathrm{~mL}$ of $\mathrm{KOH}$ solution $(2.5 \mathrm{M})$ was slowly added to the above solution. The reaction mixture was heated to $100^{\circ} \mathrm{C}$ and maintained at this temperature for $2 \mathrm{~h}$. The mixture was cooled down to room temperature, and the black precipitate was repeatedly washed with distilled water, and allowed to dry at $50^{\circ} \mathrm{C}$ over night. The weight of the prepared MNPs using both techniques was measured.

\section{Coating of MNPs with glycine}

One gram of glycine was dissolved in 50 $\mathrm{mL}$ of distilled water. Then, $1 \mathrm{~g}$ of the prepared MNPs was added to the previous solution. The mixture was sonicated for $2 \mathrm{~h}$. After that the magnetic nanoparticles coated with glycine was washed with distilled water and they were dried at room temperatures for $24 \mathrm{~h}$.

\section{Characterization of the prepared materials}

Characterizations of the fabricated bare MNPs and MNPs-Gly were carried out using X-ray diffractometer (XRD) to determine the crystalline structure of the particles. The transmission electron microscopy (TEM) was used for size investigation, scanning electron microscopy (SEM) for surface morphology analysis, energy dispersive X-ray analysis (EDAX) to the compositional analysis. 


\section{Removal of heavy metals}

The optimum condition for removal of heavy metal $\mathrm{Cu}^{+2}$ ions by the magnetic nanoparticles was investigated in aqueous solution at $25^{\circ} \mathrm{C}$, chemical parameters were studied as the following

\section{Effect of different pH of solution}

We studied the effect of different $\mathrm{pH}(2,4$, $6,8,10)$, where the mixture was adjusted to certain $\mathrm{pH}$ with $\mathrm{NaOH}$ or $\mathrm{HCl}$ and mixed by ultrasonication several minutes. using $10 \mathrm{ml}$ of solution that contain $\mathrm{Cu}^{+2}$ ions, its concentration $800 \mathrm{ppm}$, separately and with $0.001 \mathrm{~g}$ of MNP, on $700 \mathrm{rpm}$ magnetic stirrer, for $1 \mathrm{~h}$

\section{Effect of different concentrations of heavy metals}

We studied the effect of different concentrations (200, 400,600, 800, 1000 ppm), at optimum $\mathrm{pH}$ that we studied, using $0.001 \mathrm{~g}$ of MNP, for $1 \mathrm{~h}$.

\section{Effect of different dosages of MNPs and Gly- MNPs}

We studied the effect of different dosages of magnetic nanoparticles $(0.001,0.002,0.005,0.01$, $0.05 \mathrm{~g}$ ), at optimum $\mathrm{pH}$ and concentration that we studied.

\section{Effect of different contact time}

We studied the effect of different contact time $(30,60,120,180$ and $24 \mathrm{~h})$, at optimum $\mathrm{pH}$ ,concentration and dosage that we studied.

\section{RESULTS AND DISCUSSION}

Preparation of magnetic nanoparticles (MNPs)

The aim of this study was to fabricate magnetic nanoparticles in order to use them for removal of heavy metals. The reasons for choosing this types of nanoparticles are because they are easy to separated from the solution by using external magnet, and easy to fabricated. In this study, two different methods were ulilised to prepare MNPs, which will be discussed in the following see there

Figure 3.6 shows the prepared magnetic nanoparticles using second method in solution $(A)$, and after separation using external magnet. Figure 3.6 (C) shows the dried magnetic nanoparticles. The prepared magnetic nanoparticles were characterized using different techniques which will be discussed in the following sections.

$$
\mathrm{FeSO}_{4} \cdot 7 \mathrm{H}_{2} \mathrm{O}+\mathrm{KOH}+\mathrm{KNO}_{3} \rightarrow \mathrm{Fe}_{3} \mathrm{O}_{4(\mathrm{~s})}+\mathrm{K}_{2} \mathrm{SO}_{4}+\mathrm{H}_{2} \mathrm{O}
$$

\section{TEM analysis}

TEM micrographs of the prepared $\mathrm{Fe}_{3} \mathrm{O}_{4}$ nanoparticles are shown in Figure 3.1. The TEM images reveal that $\mathrm{Fe}_{3} \mathrm{O}_{4}$ nanoparticles are similar in shape and appear to be uniformly dispersed and had cube shape. It clearly showed that they have distinctive outlines square.

\section{SEM-EDAX analysis}

Surface morphology of $\mathrm{Fe}_{3} \mathrm{O}_{4}$ was studied using SEM analysis, as can be seen in Figure 3.2. that shows cube shaped crystals structure of $\mathrm{Fe}_{3} \mathrm{O}_{4}$. can find that most of the particles are roughly cube and aggregate together because of their high surface energy and adhesion.

Figure 3.3 show The EDAX spectrum that shows iron and oxygen. It reveals that the iron was from magnetic $\mathrm{Fe}_{3} \mathrm{O}_{4}$
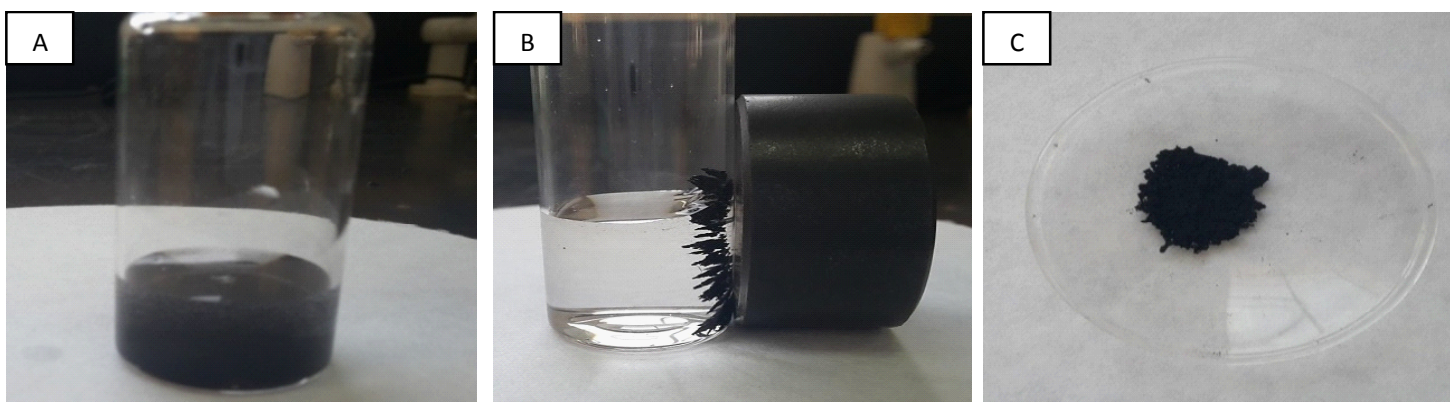

Fig. 1: Shows the prepared MNPs using second method in solution(A), after separation using external magnet, and (B) the formed dried MNPs (C) 
The elements of $\mathrm{Fe}$ and $\mathrm{O}$ can be observed in the EDAX pattern, These results demonstrate the purity of the synthesis results.

Table 3.4 shows the composition components of the formed $\mathrm{Fe}_{3} \mathrm{O}_{4}$ where the percentage of mass of $\mathrm{O}$ is $40.64 \%$, and $\mathrm{Fe}$ is $59.36 \%$, while the atom percentage of $\mathrm{O}$ is $70.50 \%$, and $\mathrm{Fe}$ is $29.50 \%$.

\section{XRD analysis}

Figure 3.4 shows the XRD spectrum of the prepared magnetic nanoparticles using second method, XRD pattern of the prepared $\mathrm{Fe}_{3} \mathrm{O}_{4}$ using
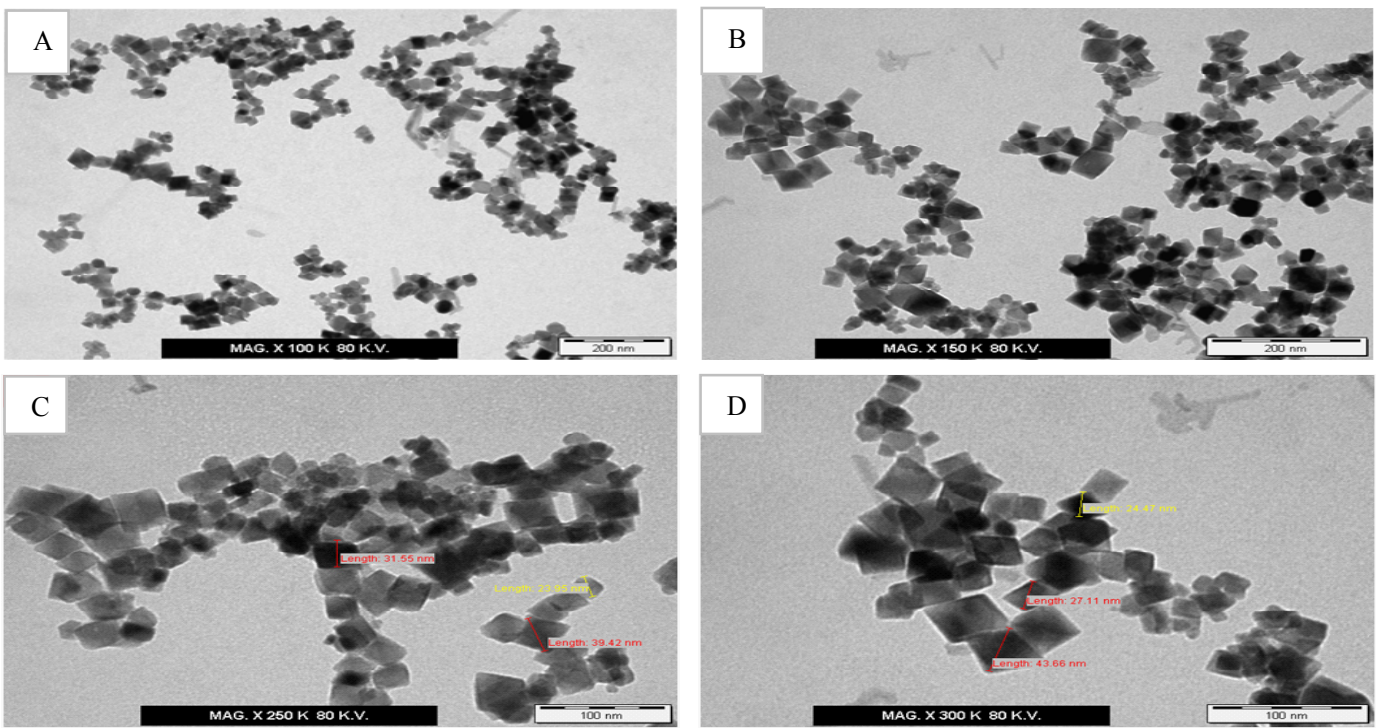

Fig. 2: TEM images of $\mathrm{Fe}_{3} \mathrm{O}_{4}$ magnetic nanoparticles at different magnifications
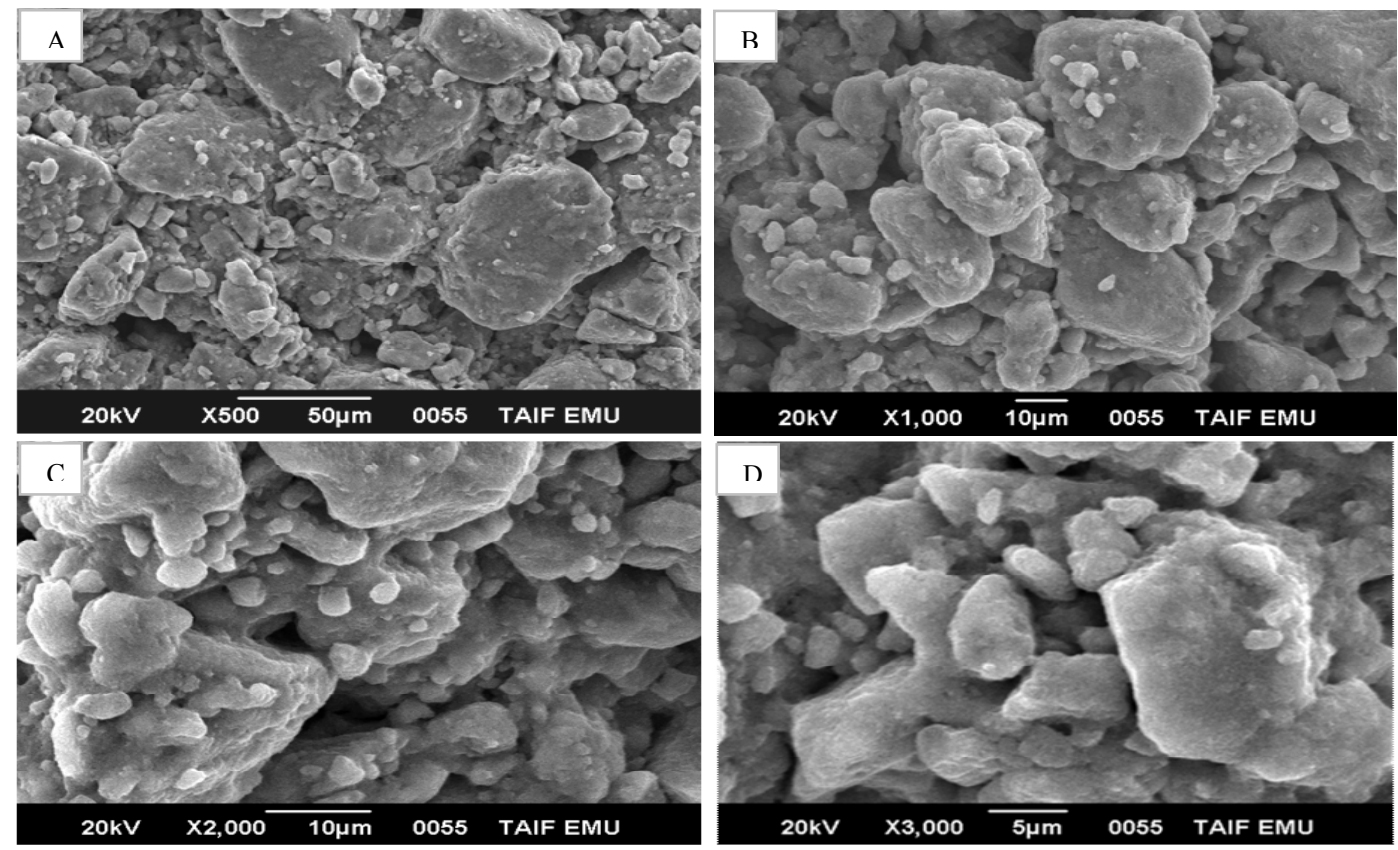

Fig. 3: SEM analysis of $\mathrm{Fe}_{3} \mathrm{O}_{4}$ magnetic nanoparticle at different magnifications 
Table 1: The composition components of the formed $\mathrm{Fe}_{3} \mathrm{O}_{4}$ using EDAX analysis

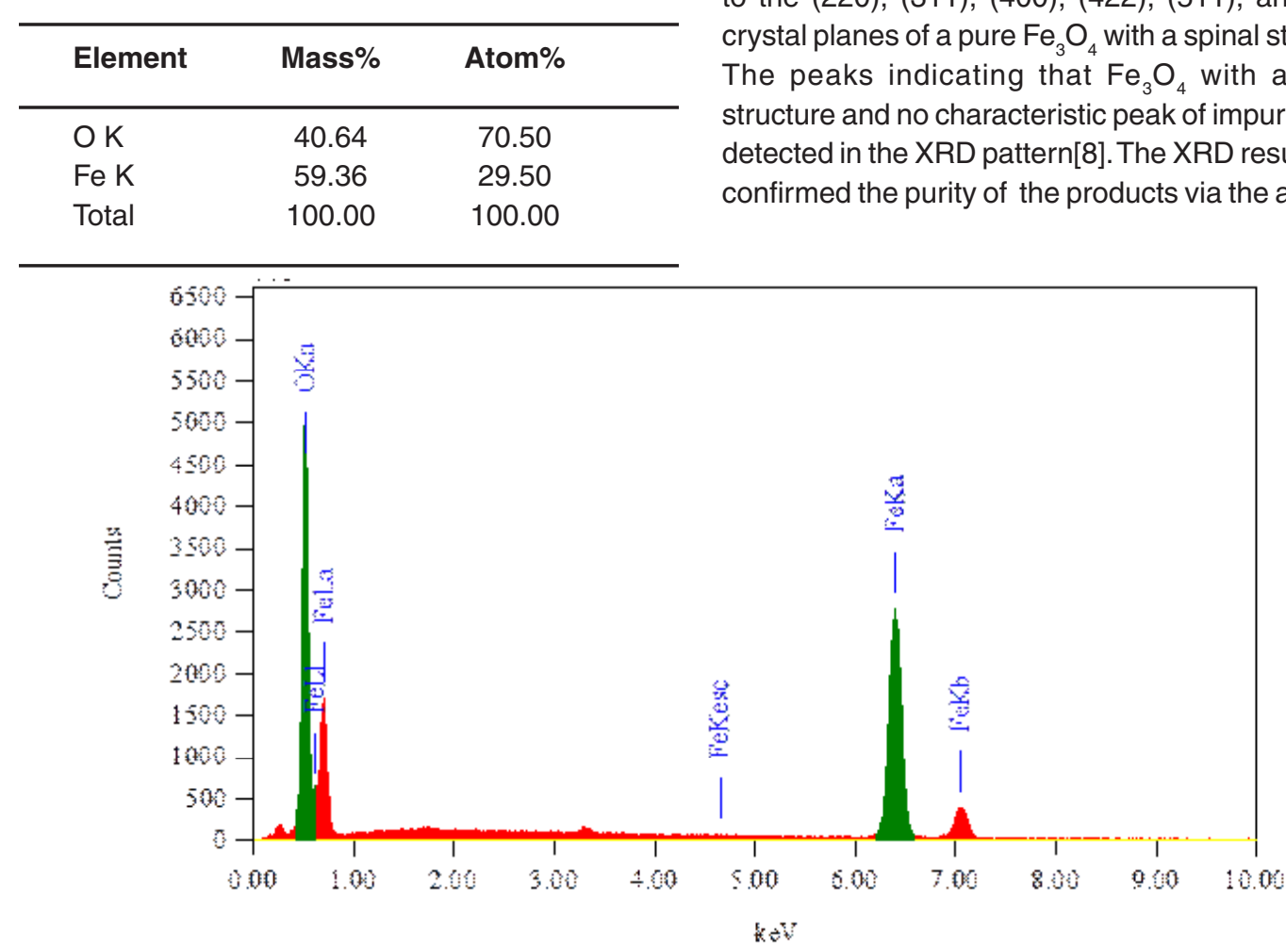

Fig. 4: Energy dispersive analysis

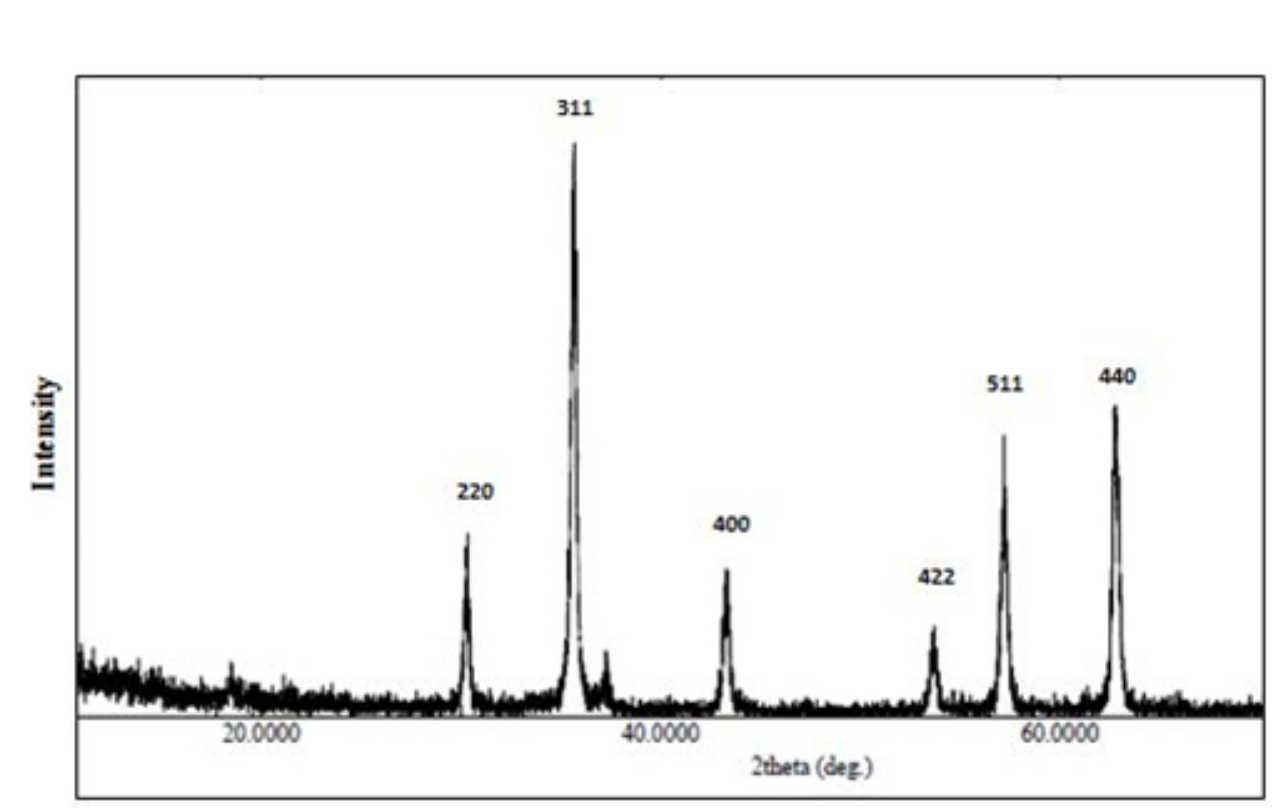

Fig. 5: X-ray diffraction patterns of $\mathrm{Fe}_{3} \mathrm{O}_{4}$ magnetic nanoparticles second method shows six characteristic peaks at $30^{\circ}, 35^{\circ}, 43^{\circ}, 53^{\circ}, 57^{\circ}$, and $62^{\circ}$ were corresponding to the (220), (311), (400), (422), (511), and (440) crystal planes of a pure $\mathrm{Fe}_{3} \mathrm{O}_{4}$ with a spinal structure. (1) confirmed the purity of the products via the absence 
Table 2: The composition components of the formed $\mathrm{Fe}_{3} \mathrm{O}_{4}$

\begin{tabular}{lcc}
\hline Element & Mass(\%) & Atom(\%) \\
\hline C K & 17.63 & 33.91 \\
O K & 31.06 & 44.86 \\
Fe K & 51.31 & 21.23 \\
Total & 100.00 & 100.00 \\
\hline
\end{tabular}

of other phases of iron oxide such as maghemite or hematite in sample

Coating of magnetic nanoparticles MNPs with glycine

Surface modification of magnetic nanoparticles is a challenged key for different applications and can be accomplished by physical/ chemical adsorption of organic compounds[9].

Coating of magnetic nanoparticles can decrease the toxicity of MNPs through decreases the
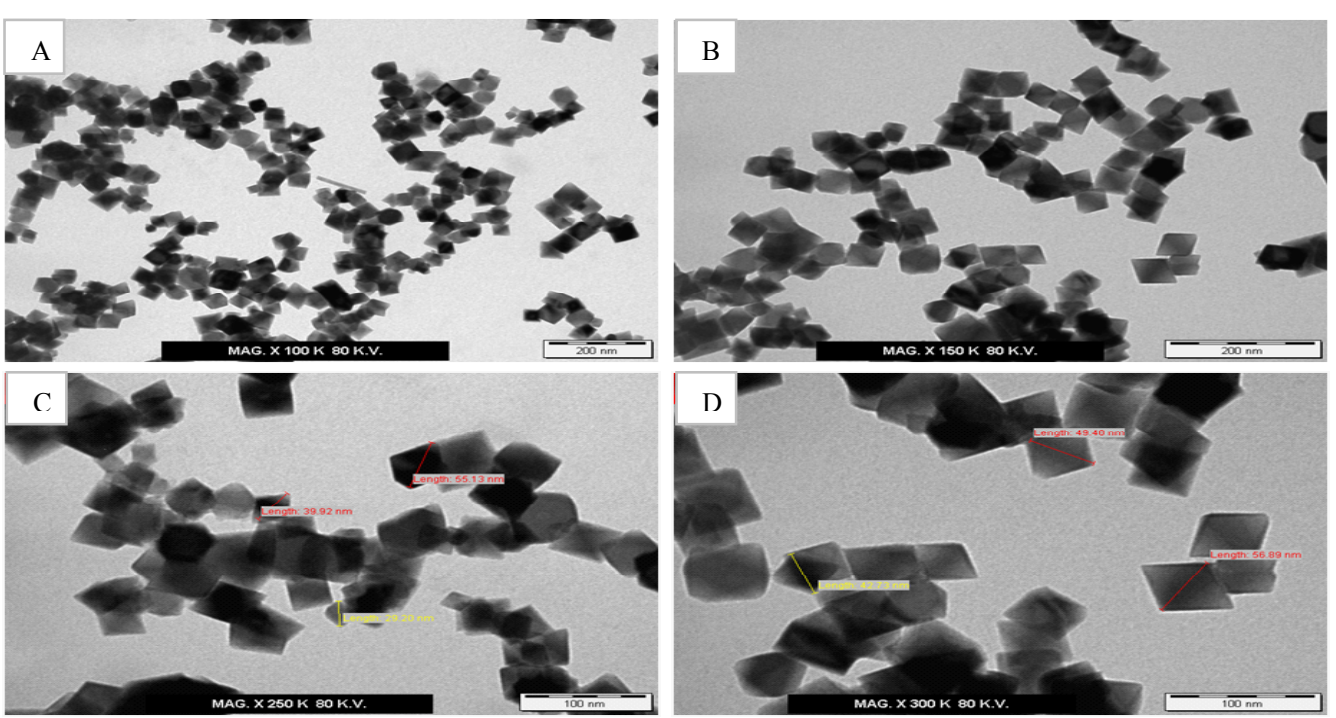

Fig. 6: TEM images of $\mathrm{Fe}_{3} \mathrm{O}_{4}$ magnetic nanoparticles coting with glycin
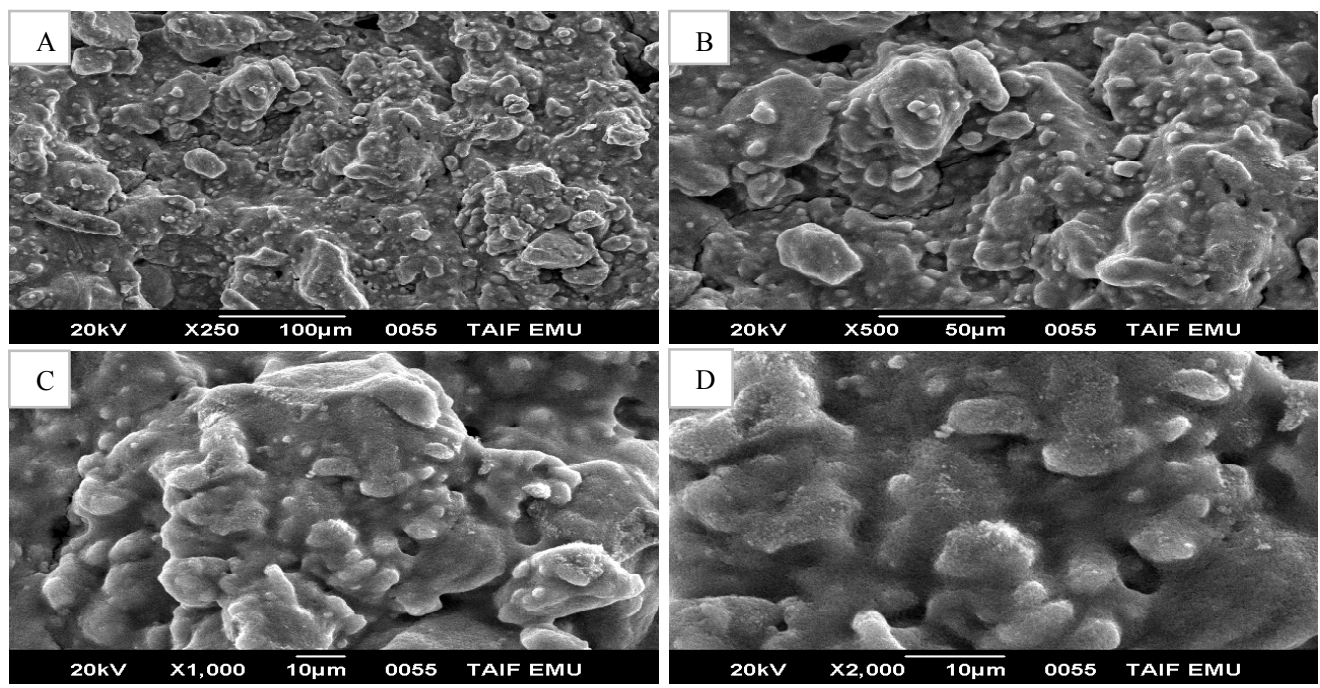

Fig. 7: $\mathrm{SEM}$ analysis of $\mathrm{Fe}_{3} \mathrm{O}_{4}$ magnetic nanoparticle coating with glycin 
saturation magnetization and increases the particle volume. It is important to consider that smallest particles present highest adsorption capabilities and high magnetizations optimize the magnetic

Table 3: Effect of different pH on the removal of $\mathrm{Cu}^{+2}$ using Gly-MNPs

\begin{tabular}{lcc}
\hline PH & $\begin{array}{c}\text { \%Up take } \\
\text { of MNPs }\end{array}$ & $\begin{array}{c}\text { \%Up take of } \\
\text { Gly- MNPs }\end{array}$ \\
\hline 2 & 41.25 & 50 \\
4 & 63 & 65 \\
6 & 75.1 & 85 \\
8 & 80 & 97.5 \\
10 & 89 & 98 \\
\hline
\end{tabular}

separation. To avoid these constraints, an alternative to polymer coatings is the chemical modification of the magnetic nanoparticle surface by small functional molecules. In this way, easily adsorbed onto the iron

Table 4: Effect of different concentrations on the removal of $\mathrm{Cu}^{+2}$ using Gly-MNPs

\begin{tabular}{lcc}
\hline $\begin{array}{c}\text { Conc. } \\
\text { (ppm) }\end{array}$ & $\begin{array}{c}\text { \%Up take } \\
\text { of MNPs }\end{array}$ & $\begin{array}{c}\% \text { Up take of } \\
\text { Gly- MNPs }\end{array}$ \\
\hline 200 & 88 & 100 \\
400 & 82.5 & 100 \\
600 & 78 & 100 \\
800 & 65 & 100 \\
1000 & 63 & 87 \\
\hline
\end{tabular}

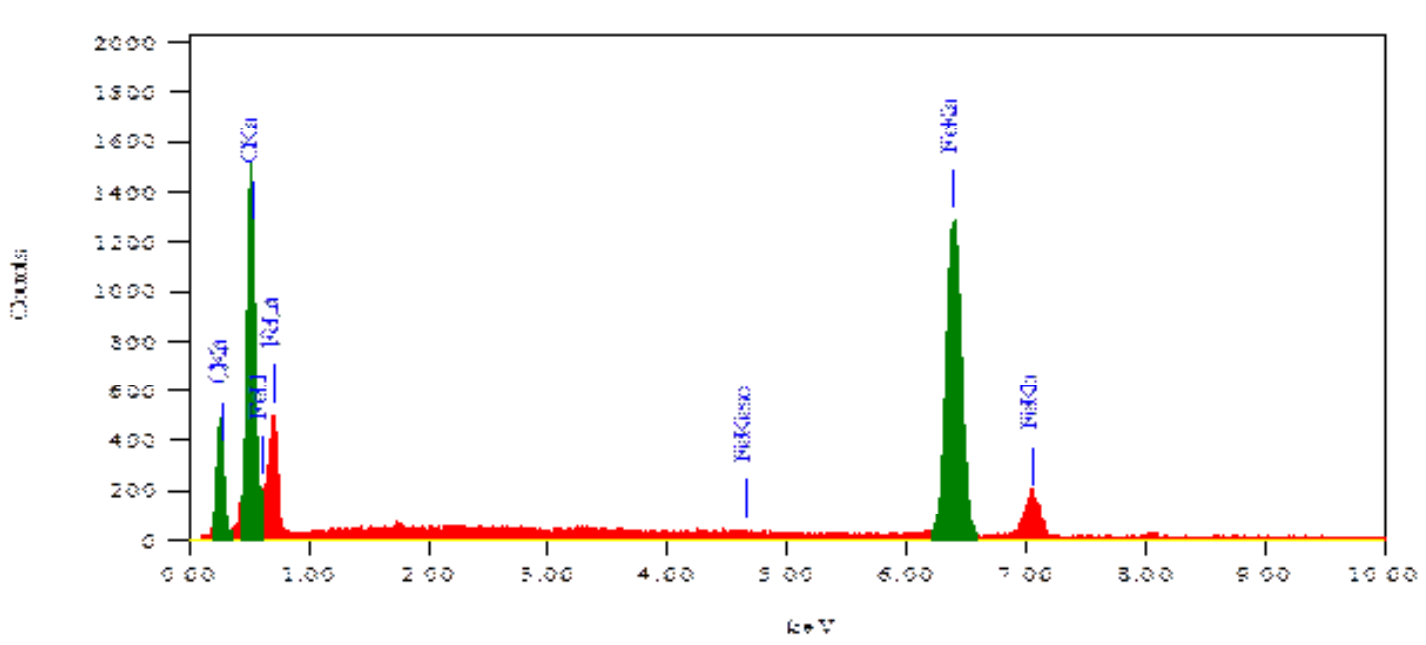

Fig. 8: Energy dispersive analysis of X-ray spectrum (EDAX) of Gly-MNPs

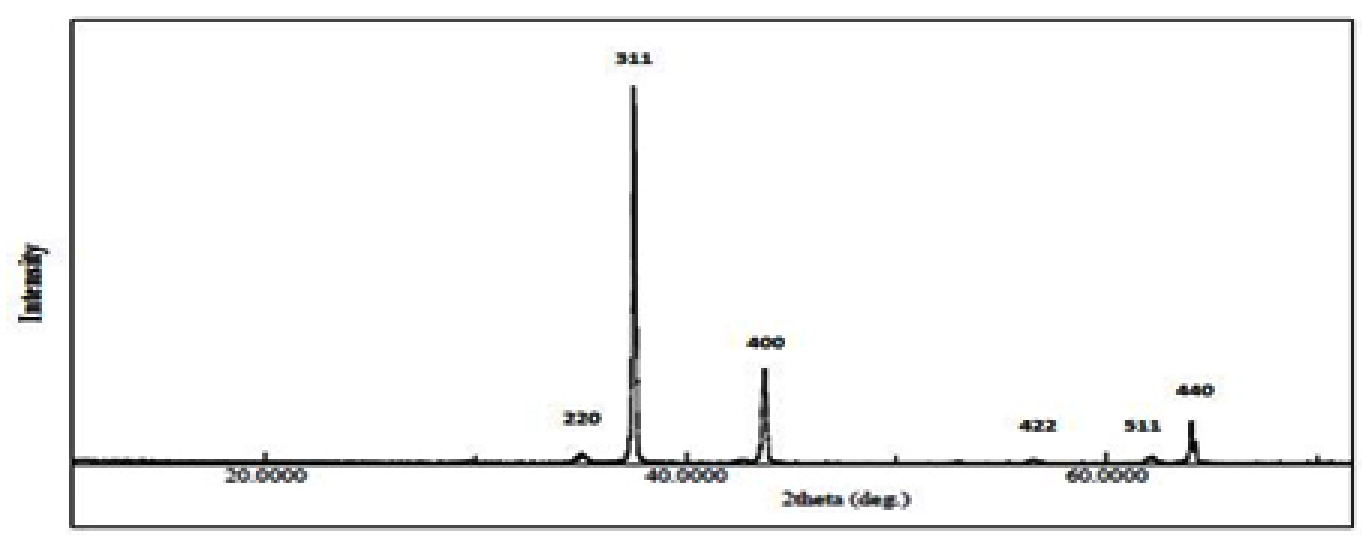

Fig. 9: X-ray diffraction patterns of coated magnetic nanoparticles 
Table 5: Effect of different dosages on the removal of $\mathrm{Cu}^{+2}$ using Gly-MNPs

\begin{tabular}{lcc}
\hline Dose (g) & $\begin{array}{c}\text { \%Up take } \\
\text { of MNPs }\end{array}$ & $\begin{array}{c}\text { \%Up take of } \\
\text { Gly- MNPs }\end{array}$ \\
\hline 0.001 & 46.66 & 62.4 \\
0.002 & 54.6 & 77.9 \\
0.005 & 64 & 86.8 \\
0.01 & 71.7 & 93 \\
0.05 & 88 & 100 \\
\hline
\end{tabular}

oxide surface, and $\mathrm{NH}_{2}$ groups at surface that could interact with the bio-environment. In fact, the potential of amine functionalized magnetic nanoparticles was already evidenced for magnetic removal of organic contaminants and heavy metals in water treatment ${ }^{10}$.

TEM analysis

TEM measurements showed that synthesis yields nearly cubic Gly-MNPs and regular in shape, and close in size dramatically. Moreover, there is

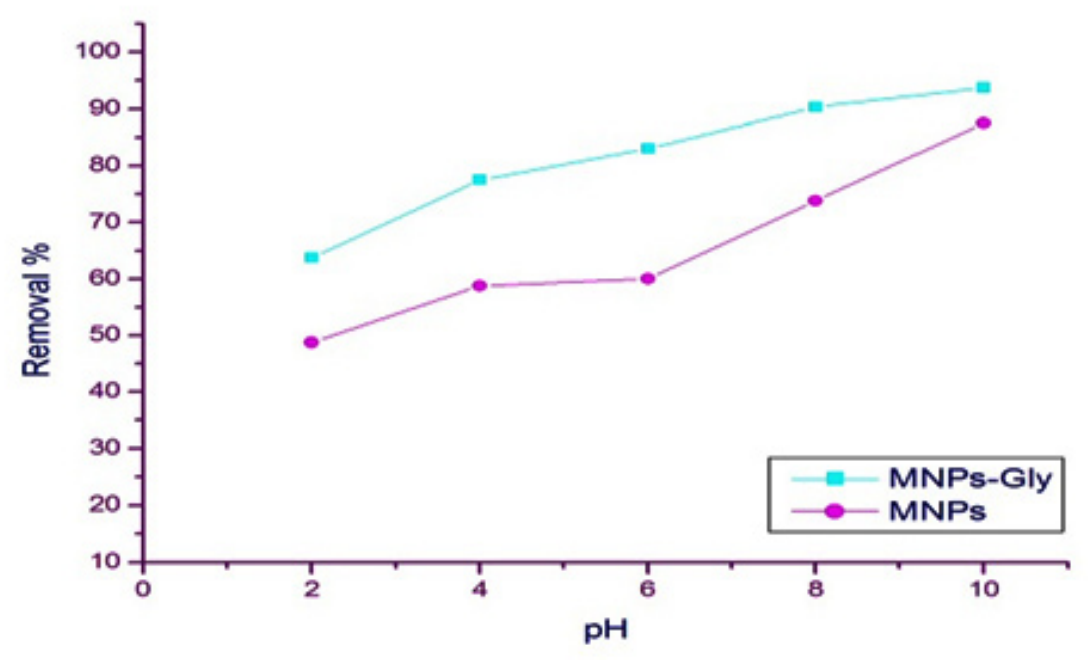

Fig. 10: Effect of different pH on the removal of $\mathrm{Cu}^{+2}$ using Gly-MNPs

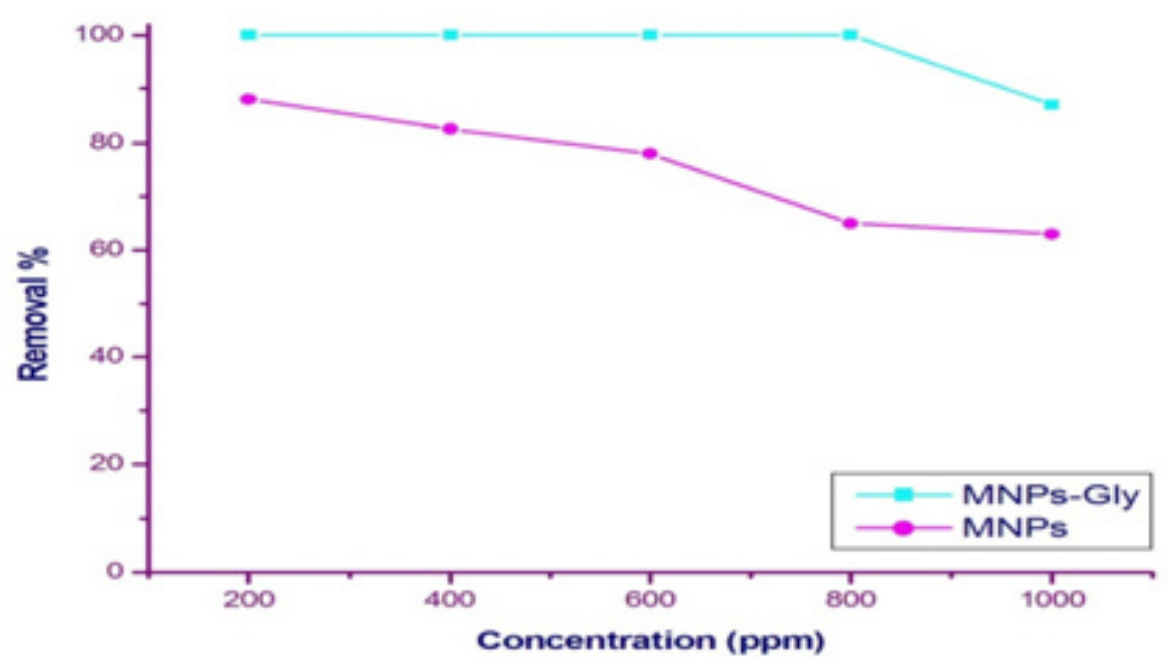

Fig. 11: Effect of different concentrations on the removal of $\mathrm{Cu}^{+2}$ using Gly-MNPs 
Table 6: Effect of contact time on the removal of $\mathrm{Cu}^{+2}$ using Gly-MNPs

\begin{tabular}{lcc}
\hline $\begin{array}{l}\text { Time } \\
\text { (h) }\end{array}$ & $\begin{array}{c}\text { \%Up take } \\
\text { of MNPs }\end{array}$ & $\begin{array}{c}\text { \%Up take of } \\
\text { Gly- MNPs }\end{array}$ \\
\hline 0.5 & 26.66 & 76.66 \\
1 & 35 & 93.3 \\
2 & 56 & 98.3 \\
3 & 78 & 100 \\
24 & 81 & 100 \\
\hline
\end{tabular}

no significant difference in shape of functionalized nanoparticles and non-functionalized ones, as showed in Figure 3.9.

\section{SEM-EDAX analysis}

Figure 3.10. image scanning electron microscope clearly shows a layer of glycine encapsulate nanoparticles compared to the previous image in Figure 3.6. where completely covered show and this proves the success of the coating of magnetic nanoparticles.

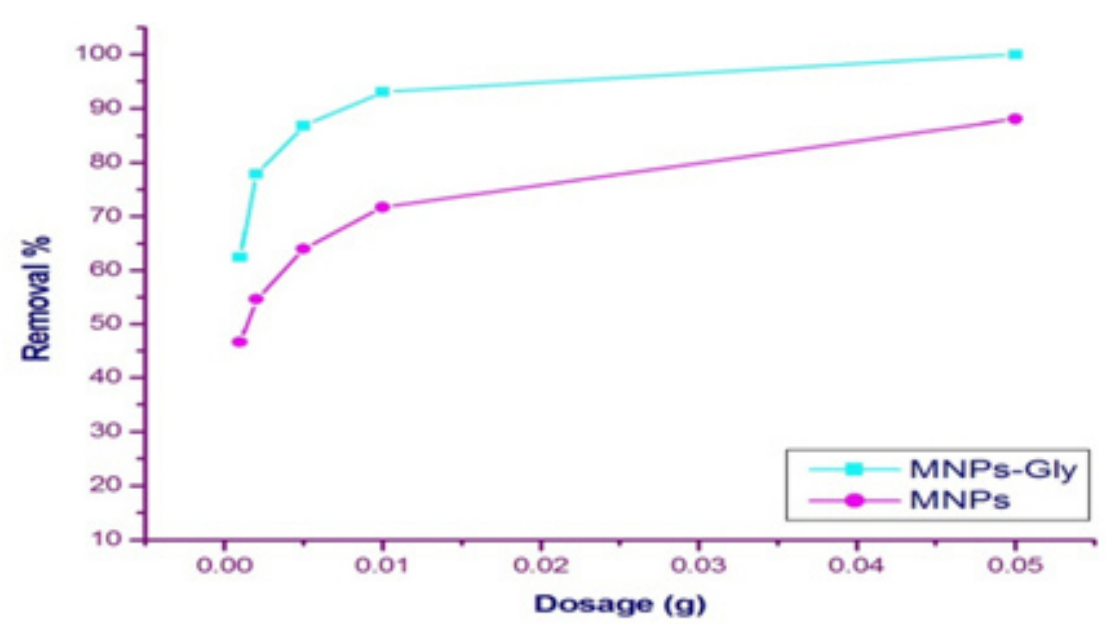

Fig. 12: Effect of different dosages on the removal of $\mathrm{Cu}^{+2}$ using Gly-MNPs

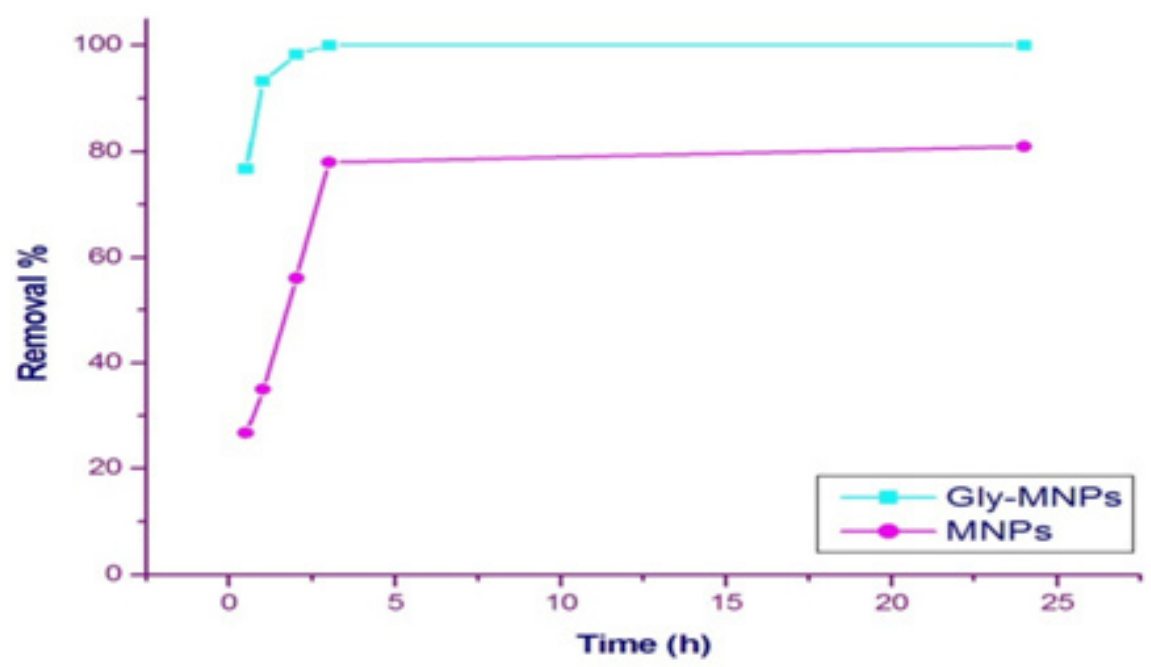

Fig. 13: Effect of contact time on the removal of $\mathrm{Cu}^{+2}$ using Gly-MNPs 
The EDAX spectrum of Gly-MNPs sample is shown in Figure 3.11, and it clearly shows the evidence of $\mathrm{Fe}, \mathrm{O}$ and $\mathrm{C}$. This result presented solid proof of the proposed structure of Gly-MNPs.

\section{XRD analysis}

Fig.3.12. shows XRD pattern of $\mathrm{Fe}_{3} \mathrm{O}_{4}$ MNPs coated with glycine.

The presence of six characteristic sharp and intense peaks confirmed the formation of highly crystalline nanoparticles. And was found there on difference with XRD result of second method.

The impact of various factors on adsorption of heavy metal ion

$$
\text { Removal efficiency }(\%)=\frac{c_{0}-c}{c_{0}} \times 100
$$

Where: $\mathrm{C}_{0}$ and $\mathrm{C}$ are the initial and residual concentrations of the heavy metal in the solution (ppm), respectively.

To obtain the optimum condition for removal of heavy metal different chemical parameters were studied as the following:

1. Effect of different $\mathrm{pH}$ of solution.

2. Effect of different concentration of heavy metals.

3. Effect of different dosage of MNPs and GlyMNPs

4. Effect of different contact time.

\section{Effect of different $\mathrm{pH}$ of solution}

As shown in tables no. 3.3. and Figures 3.10. it can be concluded that heavy metal adsorbed on the Gly-MNPs increased with $\mathrm{pH}$ value where the \%up take was $100 \%$ at $\mathrm{pH} 10$.

This observation may by due to electrostatic attraction between the negatively charged, Gly-MNPs surface and the positively charged heavy metals $\mathrm{Cu}^{+211}$.

\section{Effect of the concentrations of heavy metals}

According to Table no. 3.4. and Figure no. 3.11. we can be note that the percentage for removal heavy metal decreases from $100 \%$ to $87 \%$ with increasing concentration of heavy metal for (200$1000 \mathrm{ppm})$.

At equilibrium unit adsorption increased from (200 to $600 \mathrm{ppm}$ ), and after that the \%up take decreased, this is because the mass transfer driving force would become larger as the initial concentration increased. Hence, it results in higher heavy metals adsorption ${ }^{12}$.

\section{Effect of the dosages of MNPs and Gly-MNPs}

Table no. 3.5 and Figure no. 3.12 represent that the highest percent of removal of $\mathrm{Cu}^{+2}$ increased from (62.4 to $100 \%$ ) as the adsorbed dosage increased. Where as the adsorbent dosage increases the surface area of the adsorbent will be increased. Hence, more adsorption sites are available to adsorb heavy metals from aqueous solution ${ }^{13}$.

\section{Effect of the contact time}

From Table no. 3.6, and Figure no. 3.13 the trend of the plots show the system with take longer contact time to achieve adsorption equilibrium.

The Gly-MNPs first has to reach the boundary layer and them diffuses into the tiny pores of the adsorbent during the adsorption process. This phenomenon takes relatively longer contact time ${ }^{14}$.

\section{CONCLUSIONS}

Advances in nanoscale science and engineering are providing new opportunities to develop technology. The experimental results showed that MNPs were prepared by co-precipitation methods and different chemical analysis indicating that the MNPs coated with glycine. This study had shown that the difference between of GlyMNPs for removal of heavy metals compared with naked MNPs. The obtain Gly-MNPs was used as adsorbents for removal of heavy metals. where magnetic nanoparticles contain high surface area and large pore size for heavy metal to be adsorbed on the surface of Gly-MNPs. 


\section{REFERENCES}

1. G.-y. Li, Y.-r. Jiang, K.-I. Huang, P. Ding, and J. Chen, "Preparation and properties of magnetic $\mathrm{Fe}_{3} \mathrm{O}_{4}$-chitosan nanoparticles," Journal of alloys and compounds, vol. 466, pp. 451-456, 2008.

2. H. Parham, B. Zargar, and R. Shiralipour, "Fast and efficient removal of mercury from water samples using magnetic iron oxide nanoparticles modified with 2-mercaptobenzothiazole," Journal of hazardous materials, vol. 205, pp. 94-100, 2012.

3. S. A. Jadhav and R. Bongiovanni, "Synthesis and organic functionalization approaches for magnetite $\left(\mathrm{Fe}_{3} \mathrm{O}_{4}\right)$ nanoparticles," Adv Mat Lett, vol. 3, pp. 356-361, 2012.

4. Y. Ju-Nam and J. R. Lead, "Manufactured nanoparticles: an overview of their chemistry, interactions and potential environmental implications," Science of the total environment, vol. 400, pp. 396-414, 2008.

5. M. Mahmoudi, S. Sant, B. Wang, S. Laurent, and T. Sen, "Superparamagnetic iron oxide nanoparticles (SPIONs): development, surface modification and applications in chemotherapy," Advanced drug delivery reviews, vol. 63, pp. 24-46, 2011.

6. D. Maity and D. Agrawal, "Synthesis of iron oxide nanoparticles under oxidizing environment and their stabilization in aqueous and non-aqueous media," Journal of Magnetism and Magnetic Materials, vol. 308, pp. 46-55, 2007.

7. L. Zhang, R. He, and H.-C. Gu, "Oleic acid coating on the monodisperse magnetite nanoparticles," Applied Surface Science, vol. 253, pp. 2611-2617, 2006.

8. P. Loekitowati Hariani, M. Faizal, R. Ridwan, M. Marsi, and D. Setiabudidaya, "Synthesis and properties of $\mathrm{Fe}_{3} \mathrm{O}_{4}$ nanoparticles by co-precipitation method to removal procion dye," International Journal of Environmental Science and Development, vol. 4, pp. 336340, 2013.

9. M. Takafuji, S. Ide, H. Ihara, and Z. Xu, "Preparation of poly (1-vinylimidazole)-grafted magnetic nanoparticles and their application for removal of metal ions," Chemistry of materials, vol. 16, pp. 1977-1983, 2004.

10. N. C. Feitoza, T. D. Goncalves, J. J. Mesquita, J. S. Menegucci, M.-K. M. Santos, J. A. Chaker, et al., "Fabrication of glycinefunctionalized maghemite nanoparticles for magnetic removal of copper from wastewater," Journal of hazardous materials, vol. 264, pp. 153-160, 2014.

11. S. S. Banerjee and D.-H. Chen, "Fast removal of copper ions by gum arabic modified magnetic nano-adsorbent," Journal of hazardous materials, vol. 147, pp. 792-799, 2007.

12. J. Porath and B. Olin, "Immobilized metal affinity adsorption and immobilized metal affinity chromatography of biomaterials. Serum protein affinities for gel-immobilized iron and nickel ions," Biochemistry, vol. 22, pp. 1621-1630, 1983.

13. Y. Shen, J. Tang, Z. Nie, Y. Wang, Y. Ren, and L. Zuo, "Preparation and application of magnetic $\mathrm{Fe}_{3} \mathrm{O}_{4}$ nanoparticles for wastewater purification," Separation and Purification Technology, vol. 68, pp. 312-319, 2009.

14. J.-L. Gong, X.-Y. Wang, G.-M. Zeng, L. Chen, J.-H. Deng, X.-R. Zhang, et al., "Copper (II) removal by pectin-iron oxide magnetic nanocomposite adsorbent," Chemical Engineering Journal, vol. 185, pp. 100-107, 2012. 